\title{
GLOBALIZAÇÃO, DESTERRITORIALIZAÇÃO E RETERRITORIALIZAÇÃO
}

Hervé Théry

Directeur de recherche au CNRS-Credal. Professor Convidado na USP

Hthery@aol.com

Resumo

Palavras-chave:
Abstract

Key Words:

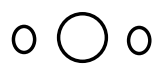

\section{INTRODUÇÃO}

As relações entre globalização e territorialidade são contraditórias, parecem ao mesmo tempo negar o território e reforçá-lo. Por um lado, parece que a competição generalizada entre todos os territórios do mundo, graças à facilidade de circulação das mercadorias, dos capitais e das informações, os coloque todos no mesmo plano. Mas por outro lado reforça a territorialidade, pela demanda de produtos "enraizados", especialmente nas agroindústrias. O território torna-se, cada vez mais, uma mercadoria, que se "vende" pelo consumo sobre in loco ou à distância, e a globalização induz, ao mesmo tempo, uma desterritorialização e uma reterritorialização do mundo.

Um dos preconceitos mais freqüentes sobre a globalização é que homogeneíza o planeta, idéia alimentada pela difusão mundial de alguns produtos e por uma certa convergência dos modos de vida, ou mais exatamente pela disseminação daqueles do “centro". É parcialmente verdadeiro, porém, ao mesmo tempo a globalização cria ou aprofunda diferenças entre países e regiões, entre os territórios que se beneficiam dela e os que são excluídos, entre territórios "vencedores" e "perdedores".

É necessário, contudo guardar-se de ver apenas, nesta reavaliação dos territórios que formam o planeta, um episódio mais de "ciclos" econômicos que o mundo já conheceu com os progressos das técnicas ou dos fluxos e refluxos dos impérios. O território não é uma simples base de apoio, contendo recursos inventariados para sempre, ele é também uma produção social, que os seus habitantes (ou outros) podem transformar e tornar mais - ou menos - atrativo e competitivo. É, portanto também um desafio, um espaço a conquistar ou defender, e um trunfo (mais ou menos valioso) que os atores que o controlam podem usar, com mais ou menos talento, no grande jogo da globalização. 


\section{O TERRITÓRIO, UMA PRODUÇÃO SOCIAL}

O território não é um mero suporte da atividade humana, ele é também uma construção social, à qual todos os seus habitantes participam, todos os dias. Certamente as iniciativas de certos atores sociais (políticos, altos funcionários ou empresários), têm um peso maior sobre o destino dos territórios: decidir da abertura de uma nova auto-estrada, da implantação de uma fábrica, da reestruturação de um bairro, estas decisões têm efeitos visíveis, estruturando e duradouros. Mas aos habitantes, mesmo os mais pobres, têm também o seu papel, freqüentemente determinante, pela massa que representam, nem que seja apenas porque se não aderem às decisões das autoridades, estas podem permanecer letra morta. Usando (ou não) à estrada, comprando (ou não) os produtos da fábrica, escolhendo (ou não) de ir habitar no bairro renovado, podem criar uma nova dinâmica espacial, ou mais um destes "elefantes brancos" denunciados nos relatórios do TCU ou nos relatórios aos acionistas. Mas se a produção de território é uma dimensão intrínseca da atividade humana, ela pode ser explícita e organizada, ao serviço de um projeto social, ou implícita, mero subproduto inevitável de atividades que têm outros fins: produzir, circular, habitar, distrair-se, etc.

É, portanto o conjunto das atividades humanas que determina a fisionomia específica de cada território e o seu lugar no grande jogo da globalização. Múltiplas configurações de poderes, in loco ou do outro lado do planeta, e determinam o que poder-se-ia chamar aqui, tomando emprestado ao vocabulário do marketing, seu "posicionamento" na competição generalizada que decorre da abertura das fronteiras. Alguns procuram valorizar as vantagens comparativas do território, desenvolver produções pelas quais são bem dotados em recursos naturais, pelas quais os seus habitantes têm qualificações que lhes permitem pô-lo no mercado ao melhor preço, ou melhor agregar valor a ele. Outros se comportam em predadores e procuram apenas explorar com o mínimo de investimento os recursos deste lugar para vendê-lo nos mercados, próximos ou remotos, capazes de pagar o melhor preço, e vêem nos habitantes do lugar apenas a mão de obra necessária, a contratar no mínimo custo possível. Alguns têm mesmo a preocupação de proteger o território, tomando cuidado para assegurar-se que os efeitos induzidos pelas atividades econômicas não criem desequilíbrios espaciais muito fortes, por que se prolonguem no tempo, de preocupar-se da solidariedade horizontal (entre as diferentes partes do território) e a solidariedade vertical (entre as gerações).

Para ilustrar, com exemplos voluntariamente contrastados, as atitudes extremas neste domínio (entre as quais se situa a maior parte dos casos observados), pode-se opor as atitudes das burguesias compradores da América latina e os camponeses egípcios. As primeiras mantêm, em boa parte, a mesma visão do território que tinham os seus antepassados conquistadores: estes consideravam o território que tinham conquistado ou recebido do Rei, bem como os seus habitantes, como um espólio a pilhar à o mais rapidamente possível para poder retornar a Espanha ou Portugal, para terminar os seus dias a gozarem nobremente da sua riqueza. Os seus descendentes enraizaram- mais se, mas apesar de terem vivido neste continente desde quatro ou cinco séculos, guardem a mesma atitude predadora, sem preocupação do longo termo, e colocam boa parte dos rendimentos tirados do território onde rendem mais, eventualmente no exterior ou em paraísos offshore. Os fellahs do vale do Nilo, pelo contrário, são estreitamente ligados à terra-mãe que os alimenta, e da qual devem manter os recursos a qualquer custo, por falta de alternativa. Esta relação estreita no entanto é ameaçada por dois fenômenos que minam-na gradualmente, as conseqüências da construção da barragem de Assouan, que prendeu o lodo que fertilizava as terras cada ano, e a urbanização que reduz gradualmente as terras suburbanas, no espaço estreito do vale. Era provavelmente o preço a pagar para o desenvolvimento do Egito moderno, mas a relação entre recursos naturais e sociedade que 
tinha sido estabelecido e mantido durante milênios se encontra profundamente afetada.

Outros exemplos poderiam ser usados (desde as velhas terras do loess chinês até todas as culturas de flores dos arredores de Bogotá e de Quito), para mostrar a diversidade dos arranjos produtivos e comerciais que se amarram e se desamarram cada dia, reforçando ou arruinando os territórios e as sociedades que vivem neles. Reclassificações, positivas e negativas, operam-se, alteram o valor relativo dos territórios, e outras são a prever nos próximos anos. Não é necessidade de ser um perito para constatar que o famoso "quando a China despertará" de Napoléon Bonaparte tornou-se uma realidade, e que ela já se tornou a fábrica do mundo. E pode-se apostar, sem grande risco de erro, analisando as reservas mundiais de terras aráveis ainda disponíveis, que a América do Sul desempenhará um papel crescente no futuro agrícola do planeta.

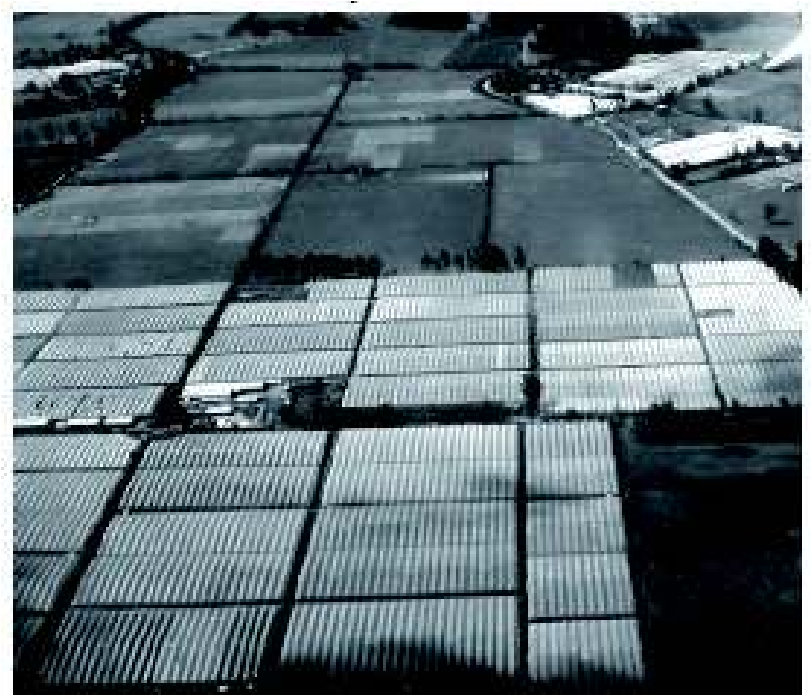

Figura 1 - Estufas de produção de flores perto de Bogotá

A competição generalizada entre os territórios do mundo, pela facilidade de circulação das mercadorias, dos capitais e das informações, parece pô-los todos no mesmo plano e, por conseguinte negar a territorialidade. Mas de outro lada ela a reforça, suscitando uma nova demanda de produtos "enraizados", especialmente no ramo das agroindústrias, e o território torna-se cada vez mais uma mercadoria, que "vende-se" para consumo in loco ou a distância: e a globalização induz, ao mesmo tempo, uma desterritorialização e uma reterritorialização do mundo.

\section{A GLOBALIZAÇÃO NEGA A TERRITORIALIDADE}

Um dos elementos evidentes da desterritorialização ligada à globalização é o aparecimento de estratégias planetárias das firmas: as montadoras de automóveis lançam e fabricam automóveis "mundiais" e ainda que a maior parte dos componentes seja produzida localmente pelas suas sucursais, alguns não são apenas estandardizados, mas circulam fisicamente pelo mundo: Toyota compra e distribui os parafusos 
necessários todas as suas fábricas, não porque trata-se de uma produção específica ou de alta tecnologia, mas porque à esta escala mundial ela obtém evidentemente preços vantajosos dos seus fornecedores.

Outras produções mais imateriais aproveitam mais facilmente ainda as economias de escala e as vantagens comparativas na escala mundial. É o caso dos centros de chamadas (call centers) e centrais de reserva das companhias aéreas, muitas das quais fixaram-se na Índia, onde as firmas encontram mão de obra anglófona, qualificada e à baixos preços.

\section{Offshore Call Center Destinations}

The Philippines

- Good English spsaking skills.

- Mushrooming call centers are putting pressure an labor supply.

- Call centers located only primarily in Manila and nearby Makati.

- High infrastructure costs

- People are completely in tune with US cultura.

India

- India has a huge reservoir of educated workforce corrfortable with English language.

- It has a 12-hour time difference with US and B 107 hours with Eurape

- Lovi labor cost but high attrition rate.

- Love infrestructure cosi

\section{South Africa}

- It is in the same time zone as the European region.

- Sharas cultural and historical affinity mith Europe.

- People proficient in European and African languages

\section{Ireland}

- Shares the same time zome as EU countries.

- Highly dereloped infrastructure.

- Well educated morkforce

- Language advantage.

Figura 2 - Vantagens comparadas de quatro países para a localização de call centers

Fonte : Choosing An Offshore Call Center Location, Shyamal Asangi and Deepali Sathe, http://www.sourcingmag.com/content/c060619a.asp

É também o caso de alguns editores, como este produtor britânico de CD-ROM, que mandou digitalizar na China a totalidade da poesia inglesa, tomando apenas a precaução de confiá-la a duas operadoras que trabalham em paralelo: um cálculo de probabilidades tinha mostrado que é quase impossível que as duas façam o mesmo erro no mesma lugar, e que seria portanto suficiente verificar, após filtragem informática, os pontos onde as duas versões divergem.

O mesmo ocorre na indústria do software, que também detectou os potenciais da Índia. As empresas indianas de tecnologia da informação realizaram 12,5 bilhões de dólares de negócios entre março de 2003 e março de 2004, ou seja 30\% mais que o ano precedente (Challenges $\mathrm{n}^{\circ} 235$, 18 de Novembro de 2004, citando a Nova Iorque Times). Os salários aumentaram de 10 a 15\% e o país vai dever enfrentar uma escassez de mão de obra qualificada de aproximadamente 250.000 pessoas. É a razão pela qual as 
sociedades indianas começam um movimento de deslocalização para a China, que forma 50.000 programadores por ano. Os salários não são muito mais baixos que na Índia, e mesmo ligeiramente superiores (embora claramente mais baixos que na Europa ou nos Estados Unidos, 145 dólares por mês na China e 125 na Índia), mas as perspectivas do mercado chinês são tais que as firmas indianas querem ser presentes: Infosys Tecnologias, cuja sede está tem Bangalore, abriu uma sucursal em Shanghai, que já conta 200 assalariados, e foi seguida pela Tata Consultancy Serviços e a Wipro Tecnologias, que visam igualmente, via esta implantação, o mercado japonês.

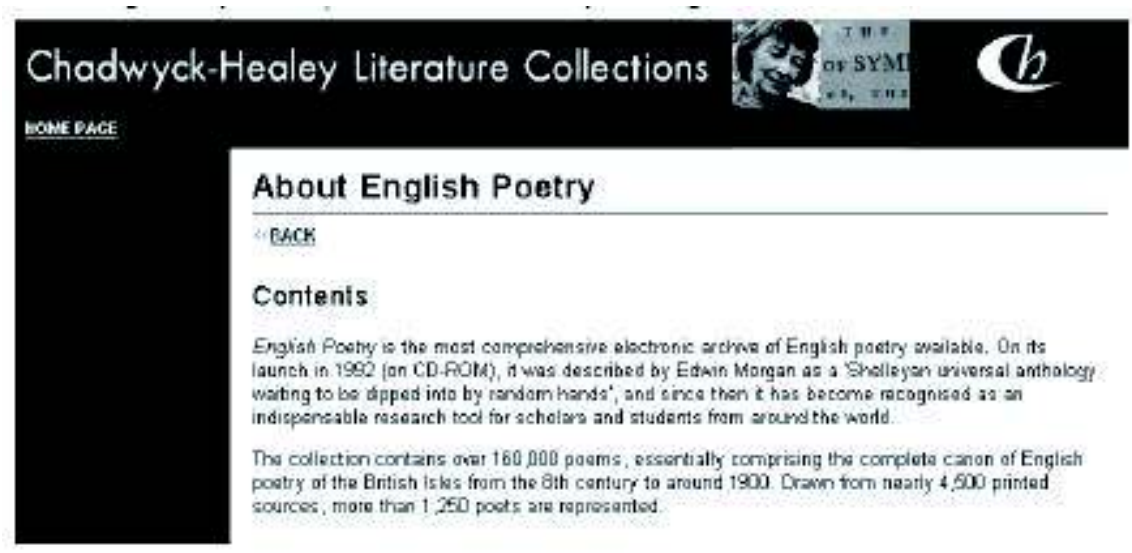

Figura 3 - Apresentação de um CD-ROM de poesia inglesa

Fonte: http://collections.chadwyck.co.uk/marketing/products/about_ilc.jsp?collection=ep2

\section{A GLOBALIZAÇÃO REFORÇA A TERRITORIALIDADE}

Simultaneamente com a abertura das fronteiras, real ou pelo menos mental, e com a divulgação de uma concepção do mundo que nega as diferenças, faz de dos territórios a base não diferenciado de uma competição planetária, aparece - com mais ou menos força — uma reivindicação de enraizamento num lugar, de uma autenticidade local, em parte em reação contra a globalização das mercadorias. E atores locais que sabem pensar globalmente conseguem aproveitar esta demanda para "vender" melhor os territórios.

Prova deste fenômeno é o sucesso das novas "denominações de origem controlada", fora os casos estabelecidos de longa data e além de países que têm de longa data praticado estas políticas de normas e de rótulos: após os vinhos e os queijos, a França classificou variedade de mel, de bolos e mesmo o feno da região da Crau, exportado por avião para emirados árabes, onde é consumido pelos cavalos puro-sangue de alguns proprietários exigentes. Na América Latina, alguns países sentiram que um esforço para diferenciar os seus produtos permitia vendê-los mais caro, ao mesmo tempo porque de fato as condições locais (solos, clima, "know-how" das populações) davam uma vantagem comparativa e porque passava a ser possível vender com eles algo da imagem do país, exótico e sedutor, como no caso do café da Colômbia. Além disso, o desenvolvimento do comércio equitativo supõe uma identificação precisa da origem, geográfica e social, dos produtores, e os consumidores que pagam de bom grado o custo adicional têm o sentimento de ajudar assim produtores pobres de países remotos, sobretudo se trata-se de produtos "orgânicos" e novos, como a quinoa andina. 


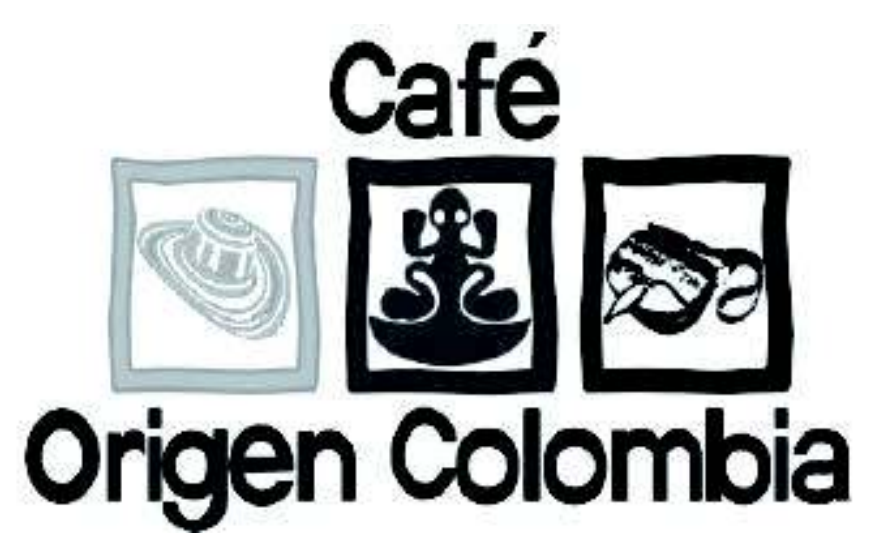

Figura 4 Vender a Colômbia ao mesmo tempo que o seu café

Pode acontecer que esta busca de produtos que veiculam a imagem de um território termine seja solapada por outros territórios melhor armados na competição mundial. É o caso dos vinhos franceses, pioneiros da denominação de origem, já que foi para eles que foram criadas as primeiras classificações ligadas à condições precisas de localização da produção. Infelizmente estas às vezes são tão refinadas, como por exemplo a dos vinhos de Bordéus, que criam nos consumidores uma certa apreensão, o medo de se perder nas distinções entre « premiers crus », « crus bourgeois » ou « passe-tout-grain » (na Borgonha esta vez). Daí o sucesso do easy drinking, o desenvolvimento, fora da França, de vinhos que permitem ao consumidor ter a certeza, ao abrir uma garrafa, de sempre encontrar o mesmo vinho, estandardizado, sem as variações dos bons e maus anos, sem os riscos ligados aos talentos desiguais dos produtores. Grandes firmas, apoiadas por enólogos qualificados, desenvolveram marcas comerciais apoiadas em territórios amplos onde a expansão de novos vinhedos é possível: da Califórnia à Austrália, passando pelo Chile e pela Argentina, os vinhos ditos genericamente "do Novo Mundo" cortam concorrência ferrenha aos produtores franceses,

Ninguém pode dizer ainda se uma reação virá, nem como ela se organizará, mas pode-se notar que outros produtores souberam responder diferentemente à demanda de autenticidade e de enraizamento implícita na de produtos locais, incluindo diretamente o "consumo" do lugar de origem, ou menos a sua freqüentação, no consumo do produto acabado. É particularmente o caso para as ofertas que florescem nos jornais destinados principalmente um leitorado de classe média ou alta, do tipo "vêm fazer o vosso foie gras (patê de fígado de ganso) na fazenda": mediante o pagamento de um preço combinado, o cliente aluga primeiro por alguns dias um quarto no hotel-fazenda, em geral um antigo prédio sem utilidade, restaurado nos padrões modernos, mas guardando ao mesmo tempo o seu encanto. Ele consome no café da manhã, no almoço e no jantar os produtos da fazenda, fabrica ele mesmo o foie gras, compra diversos produtos locais e produtos artesanais típicos, transporta-os até a cidade e os distribui entre os seus amigos, elogiando ao mesmo tempo os méritos da estada que acaba de fazer numa região preservada. Bela integração de valor agregada a um produto básico e verticalização da oferta, perfeitamente reprodutível em outros lugares: pode-se pensar em estágios de tequila no México ou de cachaça em alambiques brasileiros. 


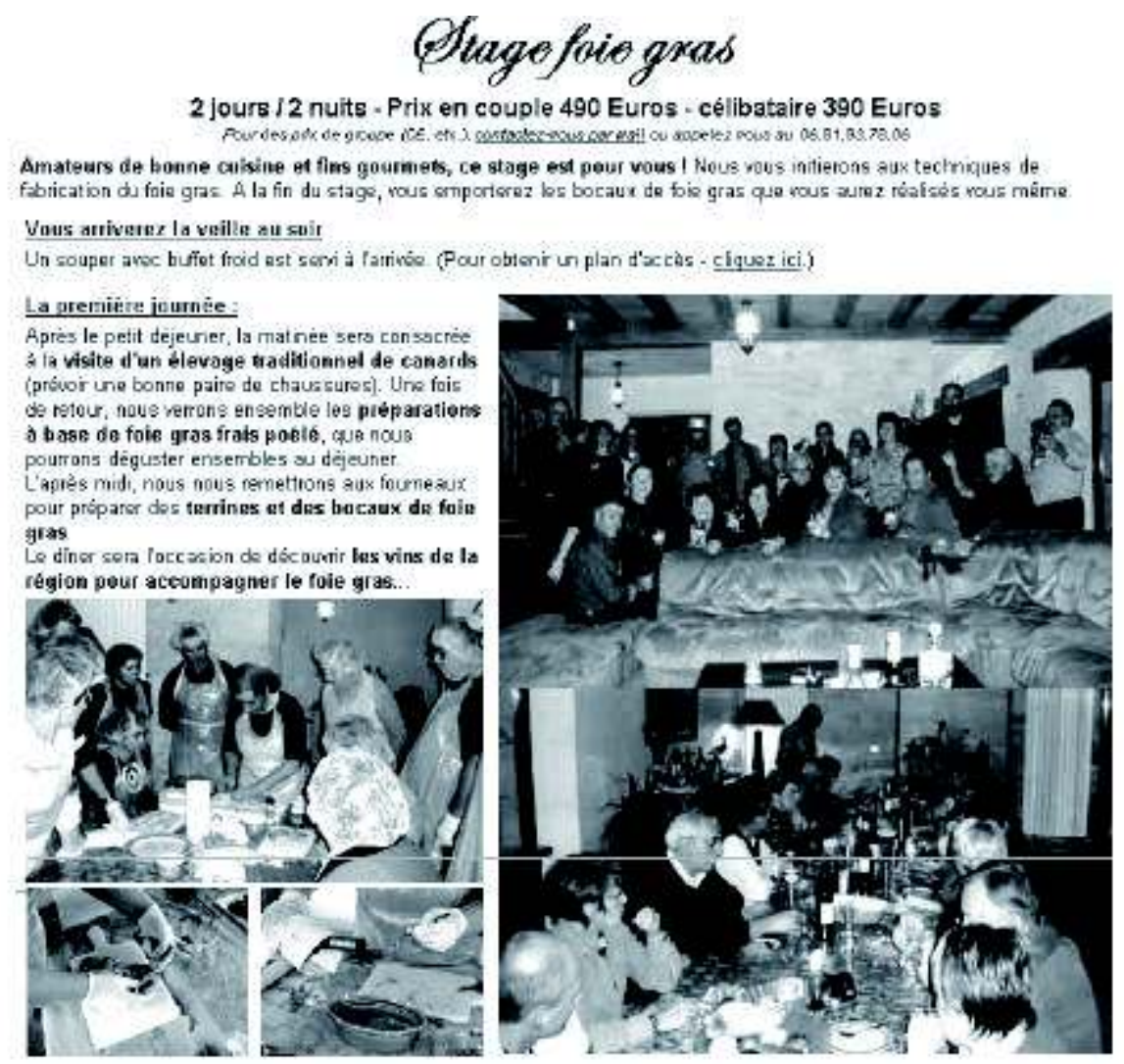

Figura 5 Estágio de foie gras na fazenda

Além destes recursos habilmente compostos, materiais e imateriais, tangíveis e simbólicos, a competição entre os territórios conduz a tentar valorizar outras vantagens, surfando entre as demandas dos mercados, espontâneas ou organizadas, as mutações tecnológicas e as dos instrumentos financeiros públicos e privados, no âmbito de um verdadeiro marketing dos territórios, que é cada dia mais uma tarefa para especialistas.

Entre estes recursos figuram naturalmente, os recursos naturais, que podem ser minerais (se o minério é procurado neste momento a um preço atrativo), agrícolas (se os preços são bons), mas também a beleza da paisagem (se esta é valorizado, como os litorais arenosos desde o desenvolvimento do turismo balneário). Mas também os recursos humanos (uma mão de obra qualificada, ou pelo menos barata), ou as vantagens ligadas às políticas locais (subvenções, normas de qualidade), para melhor e para pior (corrupção e legislação permissiva, regulamentações do trabalho e proteção do ambiente complacentes). 
Certos territórios dispõem de verdadeiras "rendas de situação", no sentido estrito do termo, ligadas à sua localização, sem que tenham a fazer o mínimo esforço. É o caso, entre as regiões de potencial turístico, daquelas que são bem colocadas em relação aos fluxos e os centros de emissão dos quais vêm os turistas potenciais. É assim que em 2007 a França recebeu 80 milhões de turistas, contra 75 em 2003, que gastaram 32,3 bilhões de dólares, ou seja 6,6\% do PIB nacional, o que fazia da França o primeiro país turístico ao mundo (de acordo com a Secretaria de turismo). No mesmo ano o Brasil, apesar todas as de atrações turísticas, da baía de Rio de Janeiro às praias paradisíacas de Bahia, passando pela floresta amazônica e as cataratas de Iguaçu, recebia meros quatro milhões, que lhe trouxeram 3,4 bilhões de dólares. É obviamente um efeito de situação, já que perto da metade dos turistas que visitam a França ficam menos de três dias (18\% uma única noite, $18 \%$ duas noites e $13 \%$ três noites). São em boa parte vizinhos, vindos outros países europeus e que aproveitam a proximidade e a facilidade de acesso, ou até mesmo que atravessam a França para ir passar ferias num outro país. O segundo e o terceiro país no ranking mundial, Espanha e México, receberam respectivamente 52,5 e 18,7 milhões de turistas, uma pelas mesmas razões que a França, o outro graças à proximidade dos Estados Unidos.

A situação é a mesma em relação a eixos e redes de circulação, num mundo cada vez mais reticular: ser colocado encima de um eixo importante - ou pelo menos perto dele — oferece muitas possibilidades, mesmo se as razões de ser deste eixo não têm nada a ver com o lugar e liga apenas um ponto A um ponto B, passando por ele. Apenas é necessário evitar o "efeito túnel", que faz que o eixo atravesse o território sem que ele possa aproveitá-lo, como no caso de uma ferrovia de trem-bala sem estação ferroviária, uma auto-estrada sem entrada ou uma linha de alta tensão sem subestação. Vale até para os eixos de circulação da informação numérica, aqueles que são aparentemente desencarnado e transportam apenas informação, na forma de seqüências de " 0 " e de " 1 ", na forma de impulsos elétricos ou luminosos, nas fibras ópticas ou nos backbones de Internet. Mesmo o mundo virtual tem a sua geografia, e mesmo neste mundo é melhor estar perto do eixo que distante dele, conectado que encravado...

Recebido em abril de 2008

Aceito em agosto de 2008 